\title{
FIBRINOLYTIC ENZYME SYSTEM IN INFANTILE ECZEMA
}

\author{
KAZUYA YAMAMOTO*, AKIKAZU TAKADA** and KANEO YAMADA*** \\ Department of Dermatology, School of Medicine, \\ Keio University, Tokyo
}

(Received for publication July 13,1965 )

In studying the mechanisms of the several skin diseases due to allergic reactions the investigation of various in vitro fibrinolytic enzyme system has played and will continue to play a prominent and important role. Of the many such methods which are available, the determination of blood fibrinolytic activity by means of gel filtration (1) has been selected for examination here.

A number of studies have reported changes of blood fibrinolytic enzyme system in dermatoses and in experimental dermatitis. ${ }^{(1,2,3,4,5,6)}$ These studies, however, have mostly been performed in the serum of adults, both normal and abnormal. In several previous studies other than dermatologic field it was shown that in newborn infants the activity of fibrinolytic enzyme system is low compared to that of older children and adults. ${ }^{(7,8,9)}$ The present study consists of measurements of the fibrinolytic activity in the sera of patients with infantile eczema ranging in age from 4 months to 11 years. These results are compared to values obtained in normal infants and children. ${ }^{(10)}$

\section{MATERIALS AND METHODS}

Definition of infantile eczema: Our discussion was largely confined to the one major entity seen in early life, a group commonly designated by dermatologists and allergists as atopic dermatitis of infants.

Human serum: Venous blood from patients with infantile eczema was obtained from the antecubital or femoral vein. The blood was allowed to clot and

* Instructor of Dermatology, and Chief, Department of Dermatology, the National Children's Hospital, Tokyo.

** Department of Physiology.

*** Department of Pediatrics. 
the serum was separated after centrifugation.

Gel fltration method: Gel filtration was performed by method described previously. ${ }^{(1)}$ However, a column was $20 \mathrm{~mm}$ in diameter and $500 \mathrm{~mm}$ in height, and effluent was collected in $4.5 \mathrm{ml}$ portions.

Determination of protein concentration: Protein concentration of the fractions was determined by the modified Folin method. ${ }^{(11)}$

Determination of fibrinolytic activity: The fibrin clot lysis time by streptokinase-activated fibrinolytic enzyme system was measured. ${ }^{(12)}$

\section{RESULTS AND DISCUSSION}

Fourteen cases of infantile eczema ( 7 boys and 7 girls) were selected for the examinations. The typical patterns of protein distribution and of fibrinolytic activity were shown in Fig. 1. The diluted serum of a 6-year-old boy was

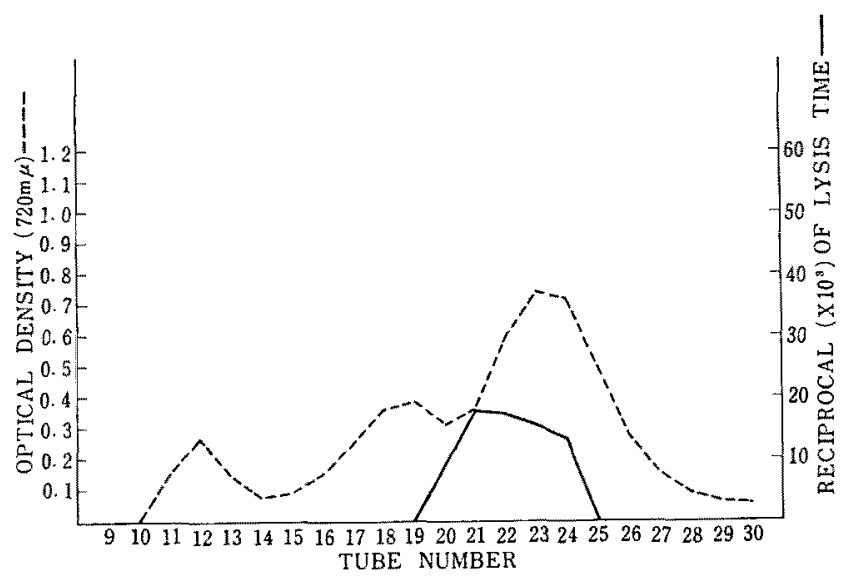

Fig. 1 Case No. 4

fractionated. Since the effuent revealed no fibrinolytic activity directly, streptokinase was added as reported earlier, ${ }^{(1)}$ and the fibrin clot lysis time was measured. The sum total of reciprocal (X 103) of lysis time of each fraction was tentatively named as Proactivator Activity, ${ }^{(10)}$ and in this case it was 72.

The results obtained from all fourteen cases were shown in Table 1.

The relationship between age and fibrinolytic activity in the plasma of normal newborn infants, older children and adults in Japanese was investigated by Takada $e t a l,{ }^{(10)}$ and the development of proactivator activity in normal state 
Table 1

\begin{tabular}{r|rr|r|l|l|c}
\hline \hline No. & \multicolumn{2}{|c|}{$\begin{array}{c}\text { Age } \\
\text { year month }\end{array}$} & Sex & Diagnosis & Severity & $\begin{array}{c}\text { Proactivator } \\
\text { Activity }\end{array}$ \\
\hline 1 & 1 & 0 & $\mathrm{~m}^{*}$ & Eczema acutum infantum & severe & 117 \\
2 & 11 & 0 & $\mathrm{f} * *$ & Atopic dermatitis with asthma & moderate & 171 \\
3 & 2 & 2 & $\mathrm{~m}$ & Atopic dermatitis & severe & 116 \\
4 & 6 & 10 & $\mathrm{~m}$ & Atopic dermatitis & moderate & 72 \\
5 & 11 & 1 & $\mathrm{f}$ & Atopic dermatitis with asthma & moderate & 144 \\
6 & 7 & 9 & $\mathrm{f}$ & Atopic dermatitis with asthma & slight & 149 \\
7 & 0 & 4 & $\mathrm{~m}$ & Atopic dermatitis & severe & 97 \\
8 & 0 & 4 & $\mathrm{~m}$ & Eczema acutum infantum & moderate & 191 \\
9 & 0 & 6 & $\mathrm{f}$ & Atopic dermatitis & severe & 80 \\
10 & 5 & 10 & $\mathrm{f}$ & Atopic dermatitis & very slight & 195 \\
11 & 1 & 11 & $\mathrm{f}$ & Atopic dermatitis & moderate & 115 \\
12 & 3 & 2 & $\mathrm{~m}$ & Atopic dermatitis & severe & 107 \\
13 & 1 & 11 & $\mathrm{~m}$ & Eczema acutum infantum & severe & 55 \\
14 & 4 & 8 & $\mathrm{f}$ & Atopic dermatitis & moderate & 105 \\
\hline
\end{tabular}

* Male

** Female

*** Sum total of reciprocal (X 103) of lysis time

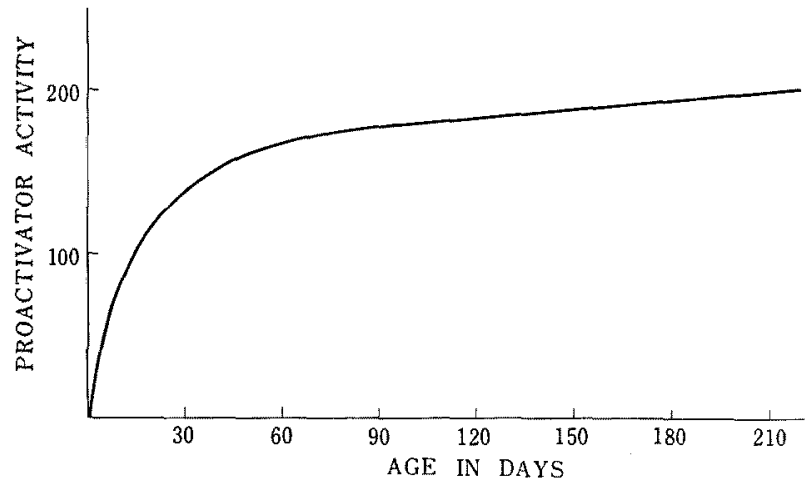

Fig. 2 Development of proactivator activity (Courtesy of Dr. Takada) 
was as shown in Fig. 2. It may be seen from the figure that the curve depicting the cumulative incidence of proactivator activity rise rapidly with increasing age, tending to flatten out as the age of 210 days in normal full-term infants is approached. As shown in Table 1 , in 11 out of 14 cases of infantile eczema the levels of their proactivator activity were less than 150 .

Many investigators have reported measurements of fibrinolytic activity in the serum of newborn infants and premature infants. ${ }^{(7,8,9,10)}$ The results of them revealed that the levels of fibrinolytic activity are low compared to those of normal adults. According to Ambrus et $a l^{(9)}$ in the postnatal period plasminogen levels increase and reach a plateau at about 7 months of age corresponding to the lower level of the normal adult range, and in antiplasmin levels there are considerable variation from individual to individual. Though the serum fibrinolytic activity in early postnatal month is low as descrived above, the results of our investigations still apparently show that the patients with infantile eczema tend to have significantly lower levels of fibrinolytic activity than normal infants.

As described previously proactivator was the main source of fibrinolytic activity in some dermatoses. Therefore low level of proactivator is considered to be one of the causes of present results. On the other hand our recent experiments showed the evidence of increase of inhibitor in the serum of these patients. Several attempts to clarify the cause of this phenomenon are being performed.

\section{SUMMARY}

Measurements of fibrinolytic activity in the serum of 14 cases of infantile eczema ranging in age from 4 months to 11 years were compared to normal infant levels. Eleven out of fourteen cases revealed remarkably low values of it.

The assistance of the staff of Department of Physiology, School of Medicine, Keio University, is gratefully acknowledged.

\section{REFERENCES}

1. Yamamoto, K. et al: Keio J. Med., 13: 195, 1964.

2. Yokoyama, K. and Hatano, H.: ibid., 8: 303, 1959.

3. Hatano, H. et al: ibid., 11: 127, 1962.

4. Hatano, H. et al: ibid., 11: 167, 1962.

5. Hatano, H. and Yamamoto, K.: ibid., 12: 113, 1963.

6. Hatano, H. et al: Jap. J. Dermat. Ser. B., 73: 120, 1963.

7. Samartzis, E. A. and Cook, C. D.: Acta Paediatrica, 49: 724, 1960. 
8. Samartzis, E. A. et al: ibid., 49: 727, 1960.

9. Ambrus, C. M. et al: Pediatrics, 35: 91, 1965.

10. Takada, A. et al: in the press.

11. Lowry, O. H. et al: J. Biol. Chem., 193: 265, 1951.

12. Takada, A. et al: Keio J. Med., 13: 187, 1964. 